\title{
Diabetic retinopathy in type 1 diabetes - a contemporary analysis of 8,784 patients
}

\author{
H. P. Hammes • W. Kerner • S. Hofer • O. Kordonouri • \\ K. Raile $\cdot$ R. W. Holl • \\ on behalf of the DPV-Wiss Study Group
}

Received: 20 December 2010 /Accepted: 28 April 2011/Published online: 3 June 2011

(C) Springer-Verlag 2011

\begin{abstract}
Aims/hypothesis The aim of this study was to analyse the risk profile for diabetic retinopathy under real-life conditions in a large cohort of patients with type 1 diabetes. Methods Patients $(n=18,891)$ with childhood, adolescent or adult onset of type 1 diabetes from the prospective German Diabetes Documentation System survey were analysed. A total of 8,784 patients fulfilled the inclusion criterion, which was availability of retinopathy status. Retinopathy grading
\end{abstract}

Electronic supplementary material The online version of this article (doi:10.1007/s00125-011-2198-1) contains supplementary material, which is available to authorised users.

H. P. Hammes $(\bowtie)$

Fifth Medical Department, Medical Faculty Mannheim,

University of Heidelberg,

Theodor-Kutzer-Ufer 1-3,

68167 Mannheim, Germany

e-mail: hp.hammes@umm.de

W. Kerner

Department of Diabetes and Diseases of Metabolism,

Heart and Diabetes Center Mecklenburg-Vorpommern,

Karlsburg, Germany

S. Hofer

Department of Pediatrics, Medical University of Innsbruck, Innsbruck, Austria

O. Kordonouri

Diabetes Center for Children and Adolescents,

Children's Hospital auf der Bult,

Hannover, Germany

K. Raile

Department of Pediatric Endocrinology and Diabetes,

Charité Children's Hospital,

Berlin, Germany

R. W. Holl

Department of Epidemiology, University of Ulm,

Ulm, Germany (any retinopathy, advanced retinopathy), treatment regimens and risk factors were prospectively recorded and tested as covariates by Kaplan-Meier analysis and logistic regression. Results Any retinopathy was present in $27.4 \%$ and advanced retinopathy (severe non-proliferative or proliferative diabetic retinopathy) in $8.0 \%$ of the cohort. After 40 years of diabetes, the cumulative proportion of patients with any retinopathy and advanced retinopathy was $84.1 \%$ and $50.2 \%$, respectively. In multiple regression analysis, risk factors for any retinopathy were diabetes duration (OR 1.167 per year), $\mathrm{HbA}_{1 \mathrm{c}}>7.0 \%$ (53 mmol/mol) (OR 2.225), smoking (OR 1.295) and male sex (OR 1.187) $(p<0.0001$ for all). Young age at onset ( 5 vs 15 years at disease onset) was protective $(0.410, p<0.0001)$. No glycaemic threshold was detected for retinopathy protection. Risk factors for advanced retinopathy were duration (1.124 per year, $p<0.0001)$, male sex $(1.323, p=$ $0.0020), \mathrm{HbA}_{1 \mathrm{c}}>7.0 \%(53 \mathrm{mmol} / \mathrm{mol})(1.499, p<0.0001)$, triacylglycerol $>1.7 \mathrm{mmol} / 1(1.398, p=0.0013)$ and blood pressure $>140 / 90 \mathrm{mmHg}(1.911, p<0.0001)$.

Conclusions/interpretation The prevalence of retinopathy remains significant in type 1 diabetes. Any improvement of metabolic control and non-smoking is protective, while hypertension affects progression to severe levels under reallife conditions. These data reinforce the validity of multifactorial concepts for morbidity protection in type 1 diabetes.

Keywords $\mathrm{HbA}_{1 \mathrm{c}} \cdot$ Hypertension · Lipids · Puberty Retinopathy

$\begin{array}{ll}\text { Abbreviations } & \\ \text { DPV } & \begin{array}{l}\text { German diabetes documentation system } \\ \text { Epidemiology of Diabetes Interventions and } \\ \text { EDIC }\end{array} \\ \text { EURODlications } \\ \text { WESDR } & \begin{array}{l}\text { European Diabetes } \\ \text { Wisconsin Epidemiological Study of } \\ \text { Diabetic Retinopathy }\end{array}\end{array}$




\section{Introduction}

Before results from the DCCT started to become implemented in the daily care of patients with type 1 diabetes, diabetic retinopathy was the most frequent microvascular complication [1]. In the pre-DCCT era, the Wisconsin Epidemiological Study of Diabetic Retinopathy (WESDR) had demonstrated an almost $100 \%$ risk of developing at least mild retinopathy over a course of 30 years of diabetes, with $50 \%$ of patients having sight-threatening retinopathy [2]. Follow-up of the DCCT cohort revealed a memory effect of early euglycaemia [3]. However, subsequent reanalysis of previous groups under poor control in 25 years of follow-up revealed a persistent $83 \%$ cumulative progression rate for any retinopathy and a $42 \%$ progression rate for proliferative stages, indicating that only minor improvements were discernible following implementations of improved care [4]. In a European cohort, Hovind et al. found a 30\% long-term cumulative incidence of advanced retinopathy with an incremental improvement in the preDCCT era, not entirely explainable by metabolic control [5].

Glycaemic control and diabetes duration as the integrated measure of glycaemic exposure are firmly established risk factors for development of any retinopathy [6-8]. Blood pressure may be a risk factor for progression to advanced stages, but its role in the development of retinopathy is not entirely clear in type 1 diabetes [9]. Other risk factors have been identified such as concomitant nephropathy, male sex, smoking, BMI and dyslipidaemia [10]. The role of young age in the development of retinopathy or its progression is still unclear. Some studies have shown that young age at disease onset does not delay the progression of retinopathy, while others observed an impact $[11,12]$.

Given the progressive changes in standard care during the post-DCCT era in patients with long disease duration, a reanalysis using up-to-date large field studies is warranted. The aim of our study was to determine the prevalence and risk pattern of retinopathy in adults with type 1 diabetes. We evaluated the impact of established and suspected risk factors for retinopathy, with a focus on thresholds for glycaemia and newly proposed blood pressure cut-offs on the basis of a nationwide prospective survey [13-15].

\section{Methods}

Data collection

Data collection was performed through the German diabetes documentation system (DPV) which is a nationwide prospective survey of diabetes-related and anthropometric characteristics of patients with type 1 diabetes.
Participating centres (for list see electronic supplementary material [ESM]) and data collection approval by local authorities have been reported earlier [13-15]. Anonymous longitudinal patient records were collected until September 2009 by the documentation and quality management system. The DPV software was developed using the Microsoft Visual FoxPro 9.0 compiler [16]. Patients were included if age at diabetes onset was below 40 years, the age at the most recent documentation was between 18 and 60 years, and at least one retinal examination had been documented on the basis of the guidelines of the German Diabetes Association [17]. By September 2009, 18,891 patients from 262 diabetes centres throughout Germany and Austria were being continuously followed in the DPV initiative. Patients from centres with a retinopathy assessment rate of less than $50 \%$ were excluded, leaving 8,784 patients with type 1 diabetes consecutively registered at 141 diabetes units in Germany and Austria. Eye examinations and complete data for all covariates examined were available for 8,653 of these patients. Patient encounters (average 7.18 examinations per patient, median follow-up period 1.5 years) available for analysis totalled 62,111 .

\section{Assessment of diabetic retinopathy}

Screening and grading for the presence or absence of diabetic retinopathy was performed by trained ophthalmologists using direct funduscopy in mydriasis according to the guidelines of the German Diabetes Association (http:// www.deutsche-diabetes-gesellschaft.de/redaktion/mitteilun gen/leitlinien/EBL_Retinopathie_Update_2004.pdf), which are based on the modified Airlie House Classification [18, 19]. In brief, retinopathy is graded into mild, moderate and severe non-proliferative diabetic retinopathy, in which the key lesions are microaneurysms/dot haemorrhages (mild), venous calibre changes/beading (moderate), and microaneurysms/haemorrhages in four quadrants or venous beadings in two quadrants or intraretinal microvascular abnormalities in one quadrant (severe). Proliferative diabetic retinopathy is defined as neovascularisation from the disc or from elsewhere, vitreous haemorrhages or tractional retinal detachment. Retinal examination by binocular biomicroscopy or fundus photography was recorded in a standardised report format. For quality control purposes, rates of reported mydriasis were analysed. A total of 45 centres from which 2,114 patients entered the study reported that $83.9 \%$ (interquartile range $11.5-81.7 \%$ ) of cases were examined in mydriasis, when adjusted for numbers of patients in the study. Fundus examinations in mydriasis by a trained ophthalmologist are considered the reference standard for field studies. The $\mathrm{k}$ coefficient of inter-rater agreement extended to 1.0 in a selected participating centre. The age at the first pathological eye 
examination was used as onset of retinopathy and the worst eye determined the patient's retinopathy level.

Risk factors for diabetic retinopathy

The following independent risk factors for the development of retinopathy were analysed: age, age at diabetes onset, sex, diabetes duration, $\mathrm{HbA}_{1 \mathrm{c}}$, hypertension, dyslipidaemia and self-reported smoking.

$H b A_{1 c}$ Glycaemic control was assessed as most recent and long-term $\mathrm{HbA}_{1 \mathrm{c}}$. Single-centre $\mathrm{HbA}_{1 \mathrm{c}}$ values were mathematically standardised according to the DCCT reference range of $4.05-6.05 \%(20.7-42.6 \mathrm{mmol} / \mathrm{mol})$ using the multiple of the mean method [20].

Hypertension Systolic and diastolic blood pressure was measured according to current guidelines [21]. Hypertension was diagnosed when the median of all individual blood pressure measurements was above 140 (systolic) and/or above $90 \mathrm{mmHg}$ (diastolic).

Smoking Smoking habits were asked about at each single visit. If at least one cigarette per day was reported, patients were classified as smokers. Current or previous smokers were compared with self-reported non-smokers.

Dyslipidaemia Dyslipidaemia was diagnosed if at least one lipid variable was permanently increased. Cut-offs were as follows: total cholesterol $>5.2 \mathrm{mmol} / \mathrm{l}$, LDL-cholesterol $>3.4 \mathrm{mmol} / \mathrm{l}$, HDL-cholesterol $<1.0 \mathrm{mmol} / 1$ for male patients and $1.3 \mathrm{mmol} / \mathrm{l}$ for female patients, and triacylgycerol $>1.7 \mathrm{mmol} / 1$.

\section{Statistical analysis}

The SAS 9.13 statistics software package (SAS Institute, Cary, NC, USA) was used for data evaluation and statistical analysis. For descriptive analysis, mean and standard deviation were used for normally distributed variables. Wilcoxon's rank sum test was used to compare patients without retinopathy, patients with non-proliferative retinopathy and patients with proliferative retinopathy. A $p$ value of $p<0.05$ was considered significant. Survival analysis using the Kaplan-Meier method was used to describe the occurrence of retinopathy in relation to diabetes duration, with stratification according to age at onset, sex, hypertension, dyslipidaemia or smoking status, using the logrank statistic to test for homogeneity among strata. Maximum observation time was censored for patients without retinopathy at last follow-up. Multiple logistic regression analysis was used to simultaneously evaluate the relative contribu- tion of covariates to the risk of retinopathy. Odds ratios and 95\% CIs are presented. Regression analysis was adjusted for time trends during the study.

\section{Results}

Patients not included in the study were younger $(28.4 \pm 11.9$ vs $32.0 \pm 12.3$ years; $p<0.0001)$, had shorter diabetes duration $(12.1 \pm 9.9$ vs $15.4 \pm 10.8$ years; $p<0.0001)$, were predominantly male $(54.3 \%$ vs $51.9 \% ; p<0.001)$ and had less hypertension $(20.8 \%$ vs $29.2 \% ; p<0.0001)$ and less dyslipidaemia $(37.1 \%$ vs $59.2 \% ; p<0.0001)$. However, due to the cohort size and the moderate differences between groups, we consider the analysis of the patients included to be valid.

At the most recent visit, 6,281 patients (72.6\%) had no retinopathy, while $1,679(19.4 \%)$ had mild to moderate retinopathy and 693 patients $(8.0 \%)$ had severe nonproliferative or proliferative retinopathy. As depicted in Table 1, descriptive variables showed significant differences between patients with and without retinopathy. Patients in the affected groups were older, had longer diabetes duration, had been younger at diabetes onset, had higher blood pressure and had a greater incidence of dyslipidaemia. Antihypertensive and antihyperlipidaemic treatment, respectively, were more frequent in patients with than without retinopathy.

Kaplan-Meier analysis revealed that after a median duration of 40 years, $84.1 \%$ of patients had any retinopathy and $50.2 \%$ had severe non-proliferative or proliferative diabetic retinopathy (Fig. 1). Significant differences were found for the time to retinopathy when the cohort was grouped for long-term metabolic control. The subcohort with long-term $\mathrm{HbA}_{1 \mathrm{c}}$ below $6.5 \%$ (47.5 $\left.\mathrm{mmol} / \mathrm{mol}\right)$ developed retinopathy significantly later than the subcohort with $\mathrm{HbA}_{1 \mathrm{c}}$ above $6.5 \%$ (time to retinopathy 32.3 vs 27.3 years, respectively; logrank test, $\chi^{2}=58.1 ; p<0.0001$ ). When the glycaemic threshold was set as $7 \%(53 \mathrm{mmol} /$ $\mathrm{mol})$ or $7.5 \%(58.5 \mathrm{mmol} / \mathrm{mol})$, the difference in time to retinopathy increased from 5.0 to 5.5 or 5.6 years respectively, all differences being statistically highly significant $(p<$ 0.0001). Thus a linear relationship exists between glycaemia and time to retinopathy development, excluding a threshold of glycaemia below which retinopathy development could be largely prevented. Figure 2 represents the Kaplan-Meier curves of patients with long-term control below and above $\mathrm{HbA}_{1 \mathrm{c}}$ of $7 \%(53 \mathrm{mmol} / \mathrm{mol})$.

We next analysed the effect of blood pressure on time to retinopathy development using pressure cut-offs between $130 / 80$ and $150 / 95 \mathrm{mmHg}$. There was no impact of blood pressure on retinopathy development within the range studied. 
Table 1 Clinical and laboratory characteristics according to retinopathy status
Values represent mean (SE)

${ }^{\mathrm{a}}$ For $p$ value comparison according to retinopathy status (three groups, non-parametric test, Wilcoxon's test, adjusted for multiple comparisons according to Holm)

${ }^{\mathrm{b}}$ Alone or in combination

ATR, angiotensin receptor; CSII, continuous subcutaneous insulin infusion

\begin{tabular}{|c|c|c|c|c|c|}
\hline \multirow[t]{2}{*}{ Characteristic } & \multicolumn{4}{|c|}{ Patients by retinopathy status } & \multirow[t]{2}{*}{$p$ value $^{\mathrm{a}}$} \\
\hline & All patients & None & Mild & Severe & \\
\hline Patients $(n)$ & 8,653 & 6,281 & 1,679 & 693 & \\
\hline Male sex $(\%)$ & 51.8 & 51.2 & 52.9 & 54.5 & NS \\
\hline Age at last visit (years) & $31.1(0.13)$ & $28.9(0.14)$ & $38.2(0.33)$ & $40.9(0.38)$ & $<0.0001$ \\
\hline Diabetes duration (years) & $14.5(0.14)$ & $11.6(0.11)$ & $23.2(0.27)$ & $26.5(0.35)$ & $<0.0001$ \\
\hline Age at onset (years) & $16.7(0.11)$ & $17.3(0.13)$ & $15.0(0.26)$ & $14.4(0.32)$ & $<0.0001$ \\
\hline \multicolumn{6}{|l|}{ Insulin treatment } \\
\hline Insulin dose (IU/kg daily) & $0.72(0.003)$ & $0.74(0.004)$ & $0.67(0.01)$ & $0.65(0.01)$ & $<0.0001$ \\
\hline CSII $(\%)$ & 27.8 & 24.1 & 50.0 & 39.1 & $<0.0001$ \\
\hline Rapid-acting analogues (\%) & 57.1 & 56.8 & 66.2 & 58.7 & $<0.0001$ \\
\hline Long-acting analogues (\%) & 45.3 & 46.8 & 46.2 & 47.4 & NS \\
\hline \multicolumn{6}{|l|}{ Risk factors } \\
\hline $\mathrm{HbA}_{1 \mathrm{c}}(\%)$ & $8.1(0.02)$ & $8.1(0.03)$ & $8.2(0.05)$ & $8.1(0.06)$ & $<0.0001$ \\
\hline $\mathrm{HbA}_{1 \mathrm{c}}(\mathrm{mmol} / \mathrm{mol})$ & 65 & 65 & 66.1 & 65 & $<0.0001$ \\
\hline BP systolic (mmHg) & $125.2(0.16)$ & $124.1(0.17)$ & $127.0(0.4)$ & $130.7(0.7)$ & $<0.0001$ \\
\hline BP diastolic (mmHg) & $75.5(0.1)$ & $75.0(0.1)$ & $76.2(0.3)$ & $78.3(0.4)$ & $<0.0001$ \\
\hline Total cholesterol (mmol/l) & $5.03(0.01)$ & $4.99(0.2)$ & $5.07(0.03)$ & $5.26(0.04)$ & $<0.0001$ \\
\hline LDL-cholesterol (mmol/1) & $2.63(0.1)$ & $2.63(0.2)$ & $2.66(0.03)$ & $2.72(0.04)$ & NS \\
\hline HDL-cholesterol (mmol/l) & $1.66(0.1)$ & $1.63(0.3)$ & $1.69(0.02)$ & $1.74(0.03)$ & $<0.005$ \\
\hline Triacylglycerol (mmol/l) & $1.41(0.01)$ & $1.44(0.02)$ & $1.29(0.03)$ & $1.41(0.04)$ & $<0.005$ \\
\hline Smokers (\%) & 27.9 & 28.6 & 34.4 & 25.9 & $<0.0002$ \\
\hline \multicolumn{6}{|l|}{ Medication $(\%)^{b}$} \\
\hline ACE inhibitors & 9.0 & 5.6 & 22.8 & 21.1 & $<0.0001$ \\
\hline Calcium antagonists & 2.0 & 1.1 & 5.6 & 5.4 & $<0.0001$ \\
\hline Diuretics & 3.2 & 1.6 & 9.2 & 10.7 & $<0.0001$ \\
\hline Beta blockers & 4.9 & 2.6 & 13.8 & 14.8 & $<0.0001$ \\
\hline ATR blockers (sartans) & 1.5 & 1.0 & 4.5 & 3.7 & $<0.0001$ \\
\hline Statins & 5.0 & 3.1 & 13.4 & 12.5 & $<0.0001$ \\
\hline Fibrate & 0.2 & 0.2 & 0.2 & 0.6 & NS \\
\hline
\end{tabular}

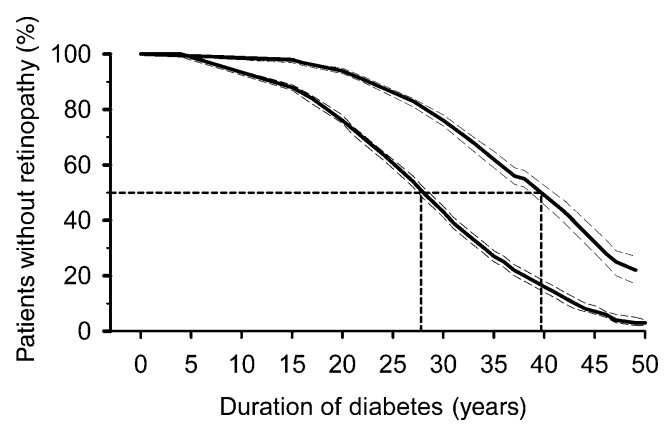

Fig. 1 Kaplan-Maier analysis relating time to occurrence of retinopathy (any vs advanced) to duration of diabetes (dashed lines on curves are $95 \% \mathrm{CI}$ ). Lower curve, any retinopathy; upper curve, advanced retinopathy. Time 0 years, $n=8,639 ; 10$ years, $n=5,172$; 20 years, $n=2,229 ; 30$ years, $n=829 ; 40$ years, $n=193$. Dashed horizontal and vertical lines indicate diabetes duration after which $50 \%$ of the cohorts were free of any (left vertical line) or advanced (right vertical line) retinopathy
Subsequently, we grouped our cohort according to age at onset of diabetes into 5-year intervals. Young age at diabetes onset ( $<5$ years) was strongly protective leading

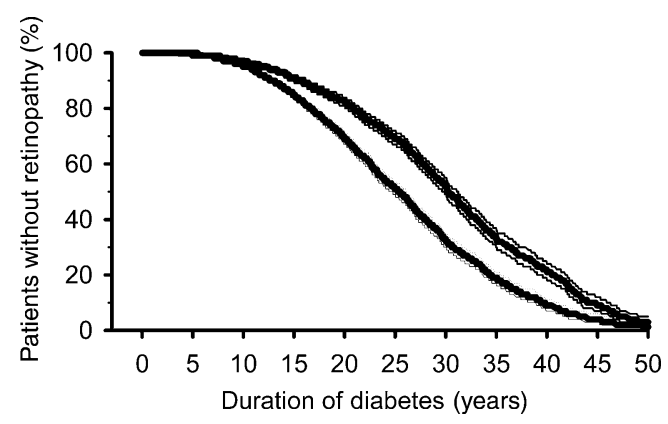

Fig. 2 Kaplan-Meier-analysis relating the occurrence of retinopathy to duration of diabetes stratified for long-term $\mathrm{HbA}_{1 \mathrm{c}}$ levels. Lower curve, $\mathrm{HbA}_{1 \mathrm{c}}>7.0 \%$ (53 mmol$\left./ \mathrm{mol}\right)$; upper curve, $\mathrm{HbA}_{1 \mathrm{c}} \leq 7.0 \%$ $(53 \mathrm{mmol} / \mathrm{mol})$. Time 0 years, $n=8,389 ; 10$ years, $n=4,943 ; 20$ years, $n=2,080 ; 30$ years, $n=761$ 
to later retinopathy development, while age at onset $>15$ years was least protective (onset $<5$ years, time to retinopathy development 31.52 years vs onset $>15$ years, time to development 26.93 years; logrank test, $\chi^{2}=67.9$; $p<0.0001)$. Univariate analysis of sex revealed a moderately earlier onset of retinopathy in males (log rank test, $\left.\chi^{2}=11.25 ; p=0.0008\right)$.

As several of the analysed factors are interrelated, a multivariable approach was used based on logistic regression analysis. The following explanatory variables were included in the model: diabetes duration, age at onset, sex, mean $\mathrm{HbA}_{1 \mathrm{c}}$, mean blood pressure, lipids and smoking. Pubertal age at onset, long diabetes duration, male sex, elevated mean $\mathrm{HbA}_{1 \mathrm{c}}$ and smoking were identified as significant independent contributors for any retinopathy (Table 2).

When four different cut-offs for blood pressure (130/80, $135 / 85,140 / 90,150 / 95 \mathrm{mmHg}$ ) were weighed separately in a logistic regression analysis only including significant risk factors, the highest blood pressure level became significant (OR 1.57, 95\% CI 1.239-1.989). When only patients with long-term $\mathrm{HbA}_{1 \mathrm{c}}$ below $7 \%(53 \mathrm{mmol} / \mathrm{mol})$ were included in the analysis, a higher risk of retinopathy development was already detectable at a threshold of $135 / 85 \mathrm{mmHg}$ (OR 1.336, 95\% CI 1.031-1.730).

Conversely, no glycaemic threshold was detectable either when analysing the entire cohort for different glycaemic levels $\left(\mathrm{HbA}_{1 \mathrm{c}} 6.5 \%\right.$ [47.5 $\left.\mathrm{mmol} / \mathrm{mol}\right], 7.0 \%$ [53 $\mathrm{mmol} / \mathrm{mol}], 7.5 \%$ [58.5 $\mathrm{mmol} / \mathrm{mol}]$ ), or upon selection of all patients with blood pressure below 140/90 mmHg. For example, the $50 \%$ point estimate of retinopathy-free survival was 31.96 years in patients with long-term $\mathrm{HbA}_{1 \mathrm{c}}$ below $7 \%(53 \mathrm{mmol} / \mathrm{mol})$.

Of the entire cohort, $8 \%$ (693 patients) had severe nonproliferative or proliferative diabetic retinopathy. In bivariate analysis, glycaemic control, blood pressure, dyslipidaemia, smoking, age at onset and diabetes duration were significantly

Table 2 Multiple logistic regression analysis, any retinopathy

\begin{tabular}{llll}
\hline Variable & OR & $95 \% \mathrm{CI}$ & $p$ value $^{\mathrm{a}}$ \\
\hline Male sex & 1.19 & $1.05-1.34$ & 0.0057 \\
Age at onset $<5$ years & 0.41 & $0.335-0.502$ & $<0.0001$ \\
$\mathrm{HbA}_{1 \mathrm{c}}>7.0 \%$ & 2.23 & $1.93-2.57$ & $<0.0001$ \\
$\quad(53 \mathrm{mmol} / \mathrm{mol})$ & & & \\
Dyslipidaemia & Removed & & \\
Hypertension & Removed & & \\
Smoking & 1.3 & $1.13-1.48$ & 0.0002
\end{tabular}

OR and 95\% CIs are given for relevant confounders of retinopathy risk; data are adjusted for duration of diabetes and year of observation Stepwise procedure was used to select significant modifiable risk factors at $p<0.05$

${ }^{\mathrm{a}}$ Refers to $\chi^{2}$ statistics associated with advanced retinopathy. Logistic regression analysis confirmed all variables to be independent risk factors except for smoking (Table 3). The highest relative risks were found for hypertension (OR 1.70, 95\% CI 1.34-2.16), dyslipidaemia (OR 1.58, 95\% CI 1.31-1.90) and glycaemia (OR 1.52, 95\% CI 1.26-1.84). In a subanalysis of lipid abnormalities, elevated triacylglycerol and LDL-cholesterol remained significant for severe retinopathy.

In multiple logistic regression analysis in which all significant risk factors were considered, the risk was significantly elevated for hypertension ( $\mathrm{BP}>140 / 90 \mathrm{mmHg}$ ): OR $1.303,95 \%$ CI 1.084-1.568. Increased risk was even higher at BP >150/95 mmHg as cut-off: OR $1.637,95 \% \mathrm{CI}$ 1.264-2.120. Thus, in contrast to mild retinopathy, the progression to advanced retinopathy is associated with hypertension.

\section{Discussion}

Our study in adults with type 1 diabetes revealed that diabetic retinopathy is persistently frequent in patients with diabetes, with over $80 \%$ of patients being affected at disease duration of longer than 40 years. Moreover, approximately half of patients still develop some sight-threatening retinopathy. Glycaemia showed a continuous relationship with retinopathy in normotensive and hypertensive groups, while blood pressure was only associated with advanced levels of retinopathy. These data on established (glycaemia, smoking, age at onset) and new (sex) risk factors provide a representative update in the post-DCCT era in the largest cohort studied in Germany and Austria.

As shown here, the overall rate of retinopathy does not appear to decline. Similar rates of cumulative incidence of any and advanced retinopathy were reported from studies during the 1980s and 1990s $[1,2,12,22,23]$. The prevalence of retinopathy was $82 \%$ after 20 years or more of diabetes in the European Diabetes (EURODIAB) studies

Table 3 Multiple logistic regression analysis, severe retinopathy

\begin{tabular}{llll}
\hline Variable & OR & $95 \%$ CI & $p$ value $^{\mathrm{a}}$ \\
\hline Male sex & 1.25 & $1.06-1.148$ & 0.0094 \\
Age at onset $<5$ years & 0.66 & $0.51-0.86$ & 0.015 \\
HbA $_{1 \mathrm{c}}>7.0 \%(53 \mathrm{mmol} / \mathrm{mol})$ & 1.52 & $1.26-1.84$ & $<0.0001$ \\
Dyslipidaemia & 1.58 & $1.31-1.90$ & $<0.0001$ \\
Hypertension & 1.70 & $1.34-2.16$ & $<0.0001$
\end{tabular}

OR and $95 \%$ CIs are given for relevant confounders of retinopathy risk; data are adjusted for duration of diabetes and year of observation Stepwise procedure was used to select significant modifiable risk factors at $p<0.05$

${ }^{\mathrm{a}}$ Refers to $\chi^{2}$ statistics 
reported in 1994 [24]. As noted above, the follow-up of the WESDR yielded similar figures, suggesting that despite successful implementation of intensified conventional therapy and/or continuous subcutaneous insulin infusion in contemporary care in Europe and the USA, diabetic retinopathy remains the major microvascular complication in type 1 diabetes [4, 14]. Obviously, some longitudinal studies and meta-analyses have suggested an overall decline in retinopathy incidence and progression rates [25-27]. However, this may reflect the multimodal approach to microvascular complications, rather than a predominant glycaemic effect on retinopathy.

Of all factors studied, $\mathrm{HbA}_{1 \mathrm{c}}$ has the strongest impact on retinopathy development. Under real-life conditions, there is no glycaemic threshold of $\mathrm{HbA}_{1 \mathrm{c}}$ between $6.0 \%$ $(42.1 \mathrm{mmol} / \mathrm{mol})$ and $7.5 \%(58.5 \mathrm{mmol} / \mathrm{mol})$, as suggested by the DCCT and other studies [20, 28]. Thus, our field study supports the guideline that the therapeutic goal should be the best achievable glycaemic target. Since 7.5\% $(58.5 \mathrm{mmol} / \mathrm{mol})$ was identified as the level of glycaemia above which the risk of diabetic nephropathy increases in the same cohort [14], the optimum glycaemic level to target appears to be $7 \%(53 \mathrm{mmol} / \mathrm{mol})$.

As established by the DCCT/Epidemiology of Diabetes Interventions and Complications (EDIC) study, glycaemic control has an extended benefit when patients switch from study conditions to standard care. In our study group, less than $16 \%$ of all patients were using less than four daily insulin injections, which is considered the threshold defined as intensified conventional therapy. In EDIC, the corresponding figure was almost identical (14\%) suggesting that highly comparable treatment modalities are being implemented in daily care [7].

Our data support the notion that a threshold blood pressure of 150/90 $\mathrm{mmHg}$ impacts on the incidence and any hypertension impacts on the development of advanced retinopathy. This is mostly consistent with other reports in adult type 1 diabetic patients [8]. However, our finding that there is a hypertensive threshold for retinopathy development is novel. Taking the size of the study group and the timelines into account, our data strongly support the multifactorial management of patients with type 1 diabetes.

The clinical question related to this is whether antihypertensive treatment is beneficial for preventing retinopathy development or delaying progression. Previous studies, in particular the EURODIAB Controlled Trial of Lisinopril in Insulin-Dependent Diabetes study, identified lisinopril to be protective against progression of pre-existing retinopathy and progression to proliferative diabetic retinopathy in normotensive, normoalbuminuric patients with type 1 diabetes [29]. No effect was demonstrated on the prevention of retinopathy. The administration of ACE inhibitors in animal models prevents the formation of acellular capillar- ies and retinal neovascularisation, underlining the relevance of this system in the pathogenesis of diabetic retinopathy [30]. In the Diabetic Retinopathy Candesartan Trials study, a significant effect of ACE inhibition using candesartan cilexetil was observed on retinopathy incidence [31].

Age at onset has been identified as important for retinopathy onset, since puberty accelerates retinopathy [32-34]. In our large cohort, onset at very young and at post-pubertal ages were protective, while onset between 5 and 15 years conferred a higher risk. The former is consistent with the concept that years of diabetes preceding puberty contribute less to retinopathy risk, while the latter is consistent with better long-term glucose control compared with pubertal patients. In a study of 339 young type 1 diabetic patients by Olsen et al., prepubertal disease duration (boys $<12.9$ years, girls $<11.7$ years) contributed half to the subsequent development of retinopathy [35]. Recent data from the FinnDiane Study, which studied the risk of proliferative retinopathy in age groups $0-4,5-14$, and above 15 years, suggest that the highest risk of advanced lesions was in the age-at-onset group 5-14 years [36]. Our study, in contrast to that finding, shows that patients in the age-at-onset group above 15 years had the least protection from advanced retinopathy despite identical mean age at diabetes onset and average diabetes duration. Since other risk factors such as smoking status or concomitant nephropathy are likely to match with our data, the cause for this observation must lie in yet unrecognised factors. Still, the question of whether young age at diabetes onset is protective for development of advanced lesions is of high practical relevance and needs to be studied further.

We found a significant relation between smoking and retinopathy. The Düsseldorf group had previously suggested an impact of smoking on microvascular disease in type 1 diabetes, while others had denied such an effect [8, 37-40]. Nevertheless, smoking rates are still high among patients with type 1 diabetes (17.3\% in the present study), and prevention programmes in adolescence and smoking cessation in general are one of the most important measures to cope with the vasculopathic burden of diabetes. The complex interaction of retinopathy with nephropathy further argues in favour of smoking cessation, as smoking may have an impact on diabetic nephropathy [41].

Dyslipidaemia was among the strongest independent risk factors for advanced retinopathy in type 1 diabetes. There is long-standing experimental evidence that elevated and biochemically altered lipids may confer cytotoxicity to retinal capillary cells [42]. Moreover, some clinical studies have suggested a link between triacylglycerol and retinopathy [43, 44]. Our contemporary large-scale analysis supports the role of lipids, in particular in progression to advanced retinopathy.

This study also provides information on the proportion of patients outside the therapeutic target. More than half of 
all patients $(56.3 \%)$ had $\mathrm{HbA}_{1 \mathrm{c}}$ levels higher than $7.5 \%$ $(58.5 \mathrm{mmol} / \mathrm{mol})$, almost one quarter $(23.9 \%)$ had dyslipidaemia and $17.3 \%$ were still smoking. Moreover, almost every sixth person was not on intensified insulin therapy and an equal number (13.5\%) had permanent hypertension, suggesting that therapeutic optimisation is of primary importance.

Despite the large number of patients and the field character of the study, certain limitations should be addressed. Thus although $100 \%$ of patients reported on had had eye examinations and a full set of variables measured under quality control criteria, they represent less than $50 \%$ of all patients with type 1 diabetes in the DPV. Furthermore, funduscopy is known to underreport retinopathy, as sensitivity is lower than fundus photography. For example, Olsen et al., using fundus photography, observed $60 \%$ retinopathy in a population of adolescents after 13 years of diabetes, albeit with average $\mathrm{HbA}_{1 \mathrm{c}}$ of $9.7 \%$ ( $\left.82.5 \mathrm{mmol} / \mathrm{mol}\right)$ [45].

In summary, this study, which is based on a large contemporary data set, provides a firm basis for epidemiological and guideline considerations. Accordingly, the focus of diabetic care should be on long-term metabolic control, together with reduction of the modifiable risk factors smoking and dyslipidaemia. For patients progressing towards more advanced stages, antihypertensive treatment is a further option.

Acknowledgements This study received financial support from the Kompetenznetz Diabetes mellitus (Competence Network for Diabetes mellitus), which is funded by the Federal Ministry of Education and Research (FKZ 01GI0859), the German Ministry of Health, German Diabetes Association, German Diabetes Foundation, German Medical Association (BÄK), Nationales Aktionsforum Diabetes Mellitus, DrBürger-Büsing-Foundation and Novo Nordisk Germany. We acknowledge the valuable contribution of the centres listed in the ESM.

Duality of interest The authors declare that there is no duality of interest associated with this manuscript.

\section{References}

1. Klein BE (2007) Overview of epidemiologic studies of diabetic retinopathy. Ophthalmic Epidemiol 14:179-183

2. Klein R, Klein BE, Moss SE, Davis MD, DeMets DL (1984) The Wisconsin Epidemiologic Study of Diabetic Retinopathy. II. Prevalence and risk of diabetic retinopathy when age at diagnosis is less than 30 years. Arch Ophthalmol 102:520-526

3. The Diabetes Control and Complications Trial/Epidemiology of Diabetes Interventions and Complications Research Group (2000) Retinopathy and nephropathy in patients with type 1 diabetes four years after a trial of intensive therapy. New Engl J Med 342:381389

4. Klein R, Knudtson MD, Lee KE, Gangnon R, Klein BE (2008) The Wisconsin Epidemiologic Study of Diabetic Retinopathy: XXII the twenty-five-year progression of retinopathy in persons with type 1 diabetes. Ophthalmology 115:1859-1868
5. Hovind P, Tarnow L, Rossing K et al (2003) Decreasing incidence of severe diabetic microangiopathy in type 1 diabetes. Diabetes Care 26:1258-1264

6. Brinchmann-Hansen O, Dahl-Jorgensen K, Sandvik L, Hanssen KF (1992) Blood glucose concentrations and progression of diabetic retinopathy: the seven year results of the Oslo study. BMJ 304:19-22

7. Writing team for the Diabetes Control and Complications Trial/ Epidemiology of Diabetes Interventions and Complications Research Group (2002) Effect of intensive therapy on the microvascular complications of type 1 diabetes mellitus. JAMA 287:2563-2569

8. Klein R, Klein BE, Moss SE, Cruickshanks KJ (1998) The Wisconsin Epidemiologic Study of Diabetic Retinopathy: XVII. The 14-year incidence and progression of diabetic retinopathy and associated risk factors in type 1 diabetes. Ophthalmology 105:1801-1815

9. Aiello LP, Cahill MT, Wong JS (2001) Systemic considerations in the management of diabetic retinopathy. Am J Ophthalmol 132:760-776

10. Cruickshanks KJ, Ritter LL, Klein R, Moss SE (1993) The association of microalbuminuria with diabetic retinopathy. The Wisconsin Epidemiologic Study of Diabetic Retinopathy. Ophthalmology 100:862-867

11. Danne T, Kordonouri O, Enders I, Hovener G, Weber B (1998) Factors modifying the effect of hyperglycemia on the development of retinopathy in adolescents with diabetes. Results of the Berlin Retinopathy Study. Horm Res 50(Suppl 1):28-32

12. Kostraba JN, Dorman JS, Orchard TJ et al (1989) Contribution of diabetes duration before puberty to development of microvascular complications in IDDM subjects. Diabetes Care 12:686-693

13. Hecker W, Grabert M, Holl RW (1999) Quality of paediatric IDDM care in Germany: a multicentre analysis. German Paediatric Diabetology Group. J Pediatr Endocrinol Metab 12:31-38

14. Raile K, Galler A, Hofer S et al (2007) Diabetic nephropathy in 27,805 children, adolescents, and adults with type 1 diabetes: effect of diabetes duration, A1C, hypertension, dyslipidemia, diabetes onset, and sex. Diabetes Care 30:2523-2528

15. Schwab KO, Doerfer J, Hecker W et al (2006) Spectrum and prevalence of atherogenic risk factors in 27,358 children, adolescents, and young adults with type 1 diabetes: crosssectional data from the German diabetes documentation and quality management system (DPV). Diabetes Care 29:218-225

16. Holl RW, Grabert M (2002) The quality circle: how to improve the outcome of paediatric diabetes care. Horm Res 57(Suppl 1):105109

17. H.-P. Hammes, B. Bertram, N. Bornfeld, T. Danne, P. Kroll, K. D. Lemmen (2004) Diagnostik, Therapie und Verlaufskontrolle der diabetischen Retinopathie und Makulopathie. Evidenzbasierte Leitlinie DDG - Aktualisierung 11/2004. Deutsche DiabetesGesellschaft. Available from www.deutsche-diabetes-gesellschaft. de/leitlinien/EBL_Retinopathie_Update_2004.pdf [In German]

18. Group Early Treatment Diabetic Retinopathy Study Research (1991) Grading diabetic retinopathy from stereoscopic color fundus photographs - an extension of the modified Airlie House classification. ETDRS report number 10. Ophthalmology 98:786806

19. Aiello LP, Gardner TW, King GL et al (1998) Diabetic retinopathy. Diabetes Care 21:143-156

20. Diabetes Control and Complications Trial Research Group (1996) The absence of a glycemic threshold for the development of longterm complications: the perspective of the Diabetes Control and Complications Trial. Diabetes 45:1289-1298

21. Mancia G, Laurent S, Agabiti-Rosei E et al (2009) Reappraisal of European guidelines on hypertension management: a European Society of Hypertension Task Force document. J Hypertens 27:2121-2158 
22. Keen H, Lee ET, Russell D, Miki E, Bennett PH, Lu M (2001) The appearance of retinopathy and progression to proliferative retinopathy: the WHO Multinational Study of Vascular Disease in Diabetes. Diabetologia 44(Suppl 2):S22-S30

23. Frank RN (2004) Diabetic retinopathy. N Engl J Med 350:48-58

24. No authors listed (1994) Microvascular and acute complications in IDDM patients: the EURODIAB IDDM Complications Study. Diabetologia 37:278-285

25. Nathan DM, Zinman B, Cleary PA et al (2009) Modern-day clinical course of type 1 diabetes mellitus after 30 years' duration: the diabetes control and complications trial/epidemiology of diabetes interventions and complications and Pittsburgh epidemiology of diabetes complications experience (1983-2005). Arch Intern Med 169:1307-1316

26. Wong TY, Mwamburi M, Klein R et al (2009) Rates of progression in diabetic retinopathy during different time periods: a systematic review and meta-analysis. Diabetes Care 32:2307-2313

27. Pambianco G, Costacou T, Ellis D, Becker DJ, Klein R, Orchard TJ (2006) The 30-year natural history of type 1 diabetes complications: the Pittsburgh Epidemiology of Diabetes Complications Study experience. Diabetes 55:1463-1469

28. Kordonouri O, Danne T, Enders I, Weber B (1998) Does the longterm clinical course of type I diabetes mellitus differ in patients with prepubertal and pubertal onset? Results of the Berlin Retinopathy Study. Eur J Pediatr 157:202-207

29. Chaturvedi N, Sjolie AK, Stephenson JM et al (1998) Effect of lisinopril on progression of retinopathy in normotensive people with type 1 diabetes. The EUCLID Study Group. EURODIAB Controlled Trial of lisinopril in insulin-dependent diabetes mellitus. Lancet 351:28-31

30. Zhang JZ, Xi X, Gao L, Kern TS (2007) Captopril inhibits capillary degeneration in the early stages of diabetic retinopathy. Curr Eye Res 32:883-889

31. Chaturvedi N, Porta M, Klein R et al (2008) Effect of candesartan on prevention (DIRECT-Prevent 1) and progression (DIRECTProtect 1) of retinopathy in type 1 diabetes: randomised, placebocontrolled trials. Lancet 372:1394-1402

32. No authors listed (1995) The relationship of glycemic exposure (HbA1c) to the risk of development and progression of retinopathy in the diabetes control and complications trial. Diabetes 44:968-983

33. Danne T, Kordonouri O, Hovener G, Weber B (1997) Diabetic angiopathy in children. Diabet Med 14:1012-1025
34. Klein BE, Moss SE, Klein R (1990) Is menarche associated with diabetic retinopathy? Diabetes Care 13:1034-1038

35. Olsen BS, Sjolie AK, Hougaard P et al (2004) The significance of the prepubertal diabetes duration for the development of retinopathy and nephropathy in patients with type 1 diabetes. J Diab Complications 18:160-164

36. Hietala K, Harjutsalo V, Forsblom C, Summanen P, Groop PH (2010) Age at onset and the risk of proliferative retinopathy in type 1 diabetes. Diabetes Care 33:1315-1319

37. Moss SE, Klein R, Klein BE (1996) Cigarette smoking and tenyear progression of diabetic retinopathy. Ophthalmology 103:1438-1442

38. Muhlhauser I, Bender R, Bott U et al (1996) Cigarette smoking and progression of retinopathy and nephropathy in type 1 diabetes. Diabet Med 13:536-543

39. Muhlhauser I, Sawicki P, Berger M (1986) Cigarette-smoking as a risk factor for macroproteinuria and proliferative retinopathy in type 1 (insulin-dependent) diabetes. Diabetologia 29:500-502

40. Nordwall M, Arnqvist HJ, Bojestig M, Ludvigsson J (2009) Good glycemic control remains crucial in prevention of late diabetic complications - the Linkoping Diabetes Complications Study. Pediatr Diab 10:168-176

41. Vergouwe Y, Soedamah-Muthu SS, Zgibor J et al (2010) Progression to microalbuminuria in type 1 diabetes: development and validation of a prediction rule. Diabetologia 53:254 262

42. Barth JL, Yu Y, Song W et al (2007) Oxidised, glycated LDL selectively influences tissue inhibitor of metalloproteinase-3 gene expression and protein production in human retinal capillary pericytes. Diabetologia 50:2200-2208

43. Chaturvedi N, Sjoelie AK, Porta M et al (2001) Markers of insulin resistance are strong risk factors for retinopathy incidence in type 1 diabetes. Diabetes Care 24:284-289

44. Sjolie AK, Stephenson J, Aldington S et al (1997) Retinopathy and vision loss in insulin-dependent diabetes in Europe. The EURODIAB IDDM Complications Study. Ophthalmology 104:252-260

45. Olsen BS, Sjolie A, Hougaard P et al (2000) A 6-year nationwide cohort study of glycaemic control in young people with type 1 diabetes. Risk markers for the development of retinopathy, nephropathy and neuropathy. Danish Study Group of Diabetes in Childhood. J Diab Complications 14:295-300 